\title{
Increased Stability of Nucleolar PinX1 in the Presence of TERT
}

\author{
Ponnarath Keo', Joong Sub Choi ${ }^{2,3}$, Jaeman Bae ${ }^{2,3}$, Yhong-Hee Shim ${ }^{1, *}$, and Bong-Kyeong $\mathrm{Oh}^{3, *}$
}

\begin{abstract}
PinX1, a nucleolar protein of 328 amino acids, inhibits telomerase activity, which leads to the shortening of telomeres. The C-terminal region of PinX1 is responsible for its nucleolar localization and binding with TERT, a catalytic component of telomerase. A fraction of TERT localizes to the nucleolus, but the role of TERT in the nucleolus is largely unknown. Here, we report a functional connection between PinX1 and TERT regarding PinX1 stability. The $C$ terminal of PinX1 $1^{205-328}$, a nucleolar fragment, was much more stable than the $\mathrm{N}$-terminal of PinX1 ${ }^{1-204}$, a nuclear fragment. Interestingly, PinX1 was less stable in TERTdepleted cells and more stable in TERT-myc expressing cells. Stability assays for PinX1 truncation forms showed that both PinX1 $1^{1-328}$ and PinX1 $1^{205-328}$, nucleolar forms, were more rapidly degraded in TERT-depleted cells, while they were more stably maintained in TERT-overexpressing cells, compared to each of the controls. However, PinX $1^{1-204}$ was degraded regardless of the TERT status. These results reveal that the stability of PinX1 is maintained in nucleolus in the presence of TERT and suggest a role of TERT in the regulation of PinX1 steady-state levels.
\end{abstract}

\section{INTRODUCTION}

Telomeres are specialized structures composed of TTAGGG repeats and telomere-specific proteins (McEachern et al., 2000). Telomerase activity is absent in most somatic cells, thereby cells cannot avoid progressive telomere attrition over each cell cycle. In contrast, germ and tumor cells exhibit preserved telomerase activity, which ensures telomere maintenance and extended proliferative potential (Djojosubroto et al., 2003; Hahn et al., 1999; Herbert et al., 1999; Zhang et al., 1999 and references therein). However, some immortal cells were found to utilize recombination mechanism to maintain telomere length in

${ }^{1}$ Department of Bioscience and Biotechnology, Konkuk University, Seoul 143-701, Korea, ${ }^{2}$ Department of Obstetrics and Gynecology, ${ }^{3}$ Institute of Medical Science, Hanyang University College of Medicine, Seoul 133791 , Korea

*Correspondence: bongoh0401@hanyang.ac.kr (BKO);

yshim@konkuk.ac.kr (YHS)

Received 22 May, 2015; accepted 29 May, 2015; published online 21 July, 2015

Keywords: nucleolus, PinX1, protein stability, TERT the absence of telomerase, from which they were termed alternative-lengthening of telomere (ALT) cells (Bryan and Reddel, 1997).

Telomerase is a ribonucleoprotein composed of TR, an RNA component, TERT, and other accessory proteins (Autexier and Lue, 1998 and references therein). TR and TERT are sufficient to provide catalytic activity in vitro (Beattie et al., 1998; Counter et al., 1998). TR is highly expressed in cells regardless of telomerase activity (Avilion et al., 1996). In contrast, TERT, a specialized reverse transcriptase that adds telomeric repeats to chromosome ends by utilizing a template region within TR, is expressed only in telomerase-positive cells, indicating that it has a rate-limiting effect on the enzyme activity (Lingner et al., 1997; Meyerson et al., 1997; Nakamura et al., 1997; Nakayama et al., 1998). TERT was found to localize to the nucleolus (Etheridge et al., 2002; Wong et al., 2002; Yang et al., 2002) and examination of endogenous TERT in cancer cells indeed revealed that a fraction resides in the nucleolus in early $S$ phase (Tomlinson et al., 2006). However, the function of TERT in the nucleolus is largely unknown.

The shelterin complex is composed of six proteins that assemble through the binding of TRF1 and TRF2, doublestranded TTAGGG repeat-binding proteins, and POT1, a single-strand telomeric DNA-binding protein (Palm and de Lange, 2008). TRF1 and TRF2 recruit other shelterin components (RAP1, TIN2, TPP1, and POT1) to the telomeres (Palm and de Lange, 2008). PinX1, a nucleolar protein of 328 amino acids, was previously identified as a TRF1 interaction partner by a yeast two-hybrid screen (Zhou and Lu, 2001). It also associates with the telomerase subunits, TERT and TR, and inhibits telomerase activity (Banik and Counter, 2004; Zhou et al., 2011). PinX1+/- mice spontaneously developed malignant tumors, displaying increased telomerase activity (Zhou et al., 2011). Consequently, overexpression of PinX1 in cancer cells resulted in telomere shortening, which impaired cell growth (Zhou and Lu, 2001). Interestingly, the depletion of PinX1 in cancer cells also causes shortening of the telomere length because of reduced binding of telomerase to the POT1-containing telomere complex (Zhang et al., 2009). In addition, PinX1 also affects the localization of telomerase on telomeres, as well as the nucleolar localization of TERT (Cheung et al., 2012; Lin et al., 2007). Such observations indicate that PinX1 is involved in the maintenance of telomere length by regulating not only the activity, but also the localization of telomerase. The precise mechanism underlying PinX1-mediated telomere regulation remains to be elucidated.

The C-terminal region of PinX1, comprised of amino acids 
290 to 328, is critical for the nucleolar localization and TERT binding (Chen et al, 2010), while residues 254-328 are responsible for TRF1 binding (Zhou and Lu, 2001). This suggests that the C-terminal of PinX1 is important for telomere maintenance, through interaction with other telomere proteins. However, the role of PinX1 in the nucleolus is unknown.

In the present study, we found that the C-terminal of PinX1, a nucleolar fragment, was more stable than the $\mathrm{N}$-terminal of PinX1, a nuclear fragment, and interestingly, TERT positively regulated the accumulation of $\mathrm{PinX} 1$ by stabilizing the protein. TERT-mediated increase in PinX1 stability was only observed for the nucleolar form of PinX1, not the nuclear form. These findings demonstrate that PinX1 is accumulated in the nucleolus by TERT via a process conferring protein stability.

\section{MATERIALS AND METHODS}

\section{Cell culture and Transfection}

HeLa cells were cultured in Dulbecco's modified Eagle's medium (DMEM) (Welgene, Korea), supplemented with $10 \%$ fetal bovine serum (Welgene), $10 \mu \mathrm{g} / \mathrm{ml}$ streptomycin and penicillin (Welgene). HeLa cells at $60-70 \%$ confluency were transfected with $1.0 \mu \mathrm{g}$ of plasmids or $50 \mathrm{nM}$ of siRNA using jetPRIME reagent, according to the manufacturer's instructions (Polyplus, France). siRNAs against TERT were purchased from Invitrogen (Stealth RNAi HSS144247, HSS144248, HSS144268, Invitrogen, USA), and the siRNA control was purchased from Genolution (Korea). A mixture of the three siRNAs against TERT was used for transfection. All plasmids tested in this study except myc-PinX $1^{1-204}$ were described in previous reports (Yoo et al., 2009; 2014). Myc-PinX $1^{1-204}$ was generated by PCR amplification using pCMV-myc-Pin $X 1^{1-328}$ as a template, and the following primers: $5^{\prime}$-GCC ATG GAG GCC CGA ATT CGG AT$3^{\prime}$ and $5^{\prime}$-CTC AGG CGG CCG CTC ACT CAG AAA TGT CAG ACC CTG GAA C-3', wherein the EcoRI and Notl sites are underlined. Amplified DNA was gel purified, digested with Eco$\mathrm{RI}$ and Notl, and ligated into pCMV-myc. A positive clone was confirmed by sequencing (Macrogen, Korea).

\section{Immunoblot and antibodies}

Cells resuspended in RIPA buffer (150 mM NaCl, 1\% NP-40, $0.5 \%$ sodium deoxycholate, $0.1 \%$ sodium dodecyl sulfate (SDS), $50 \mathrm{mM}$ Tris- $\mathrm{HCl}, \mathrm{pH}$ 8.0) containing 1X protease inhibitor mixture (Roche, Germany) were lysed by either the freezethaw method or sonication (CosmoBio, Japan). Cell lysates were fractionated by SDS-polyacrylamide gel electrophoresis and then transferred to PVDF membranes (Millipore, USA) via semidry transfer (Hoefer, USA). After blocking the membranes with $5 \%$ skim milk/2\% BSA in PBS-T (PBS with $0.1 \%$ Tween20) for $1 \mathrm{~h}$ at RT, membranes were blotted with the primary antibodies followed by secondary antibodies. Immunoblots were developed using ECL reagent (Amersham ${ }^{\circledR}$ Biotechnology, UK), according to the manufacturer's protocol. The antibodies used were mouse polyclonal anti-PinX1 (1:3000, Abnova, Taiwan), rabbit polyclonal anti-TERT (1:1000, Epitomics, USA), Rabbit anti-HA probe (1:500, Y-11, Santa Cruz), mouse anti-cmyc (1:1000, 9E10, Santa Cruz), anti-GFP (1:5000, JL-8, Clontech, USA), anti- $\beta$-actin (1:5000, Cell Signaling, USA) and antiGAPDH (1:5000, Abcam, UK). All reactions with primary antibodies were performed at $4^{\circ} \mathrm{C}$ overnight, except for $\beta$-actin and GAPDH reactions, which were carried out at RT for $1 \mathrm{~h}$. Reactions for secondary antibodies, including horseradish peroxidase-conjugated anti-mouse $\lg G$ and anti-rabbit $\lg$ (1:5000, Santa Cruz), were performed at RT for $1 \mathrm{~h}$. The blots were analyzed by the Bio-imaging Analyzer LAS4000 (Fuji-film, Japan) or ChemiDoc (Bio-Rad, USA).

\section{$R T-P C R$ and $q R T-P C R$}

Total RNA was extracted from HeLa cells using TRIzol ${ }^{\circledR}$ reagent (Invitrogen), according to the manufacturer's instructions. CDNA synthesis was performed as follows: $1.0 \mu \mathrm{g}$ of total RNA was mixed with $1.5 \mu \mathrm{l}$ of random hexamers $(80 \mathrm{pmol} / \mu \mathrm{l})$ (Takara, Japan), and $1.0 \mu \mathrm{l}$ of $10 \mathrm{mM}$ dNTPs, with water added to make $12 \mu \mathrm{l}$. The reaction was incubated at $65^{\circ} \mathrm{C}$ for $5 \mathrm{~min}$, and then $4.0 \mu \mathrm{l}$ of First Strand buffer (5X), $2.0 \mu \mathrm{l}$ of 1.0 M DTT, $1.0 \mu \mathrm{l}$ of M-MLV reverse transcriptase (Invitrogen), and $1.0 \mu \mathrm{l}$ of water were added, making the total volume $25 \mu$ l. The reaction was incubated at $25^{\circ} \mathrm{C}$ for $10 \mathrm{~min}, 37^{\circ} \mathrm{C}$ for $50 \mathrm{~min}$, and then terminated at $70^{\circ} \mathrm{C}$ for $15 \mathrm{~min}$. CDNA was also synthesized using the High Capacity cDNA Reverse Transcription Kit (Applied Biosystems, USA), according to the manufacturer's instructions. PCR reactions were performed with $1.0 \mu \mathrm{l}$ of CDNA, $10 \mu \mathrm{M}$ of each forward and reverse primer (Macrogen), and Top taq polymerase (Davinch-K, Korea), according to the manufacturer's protocol. Amplification of PinX1 derivatives consisted of one cycle at $94^{\circ} \mathrm{C}$ for $3 \mathrm{~min}, 20$ cycles at $94^{\circ} \mathrm{C}$ for $30 \mathrm{~s}, 58^{\circ} \mathrm{C}$ for $30 \mathrm{~s}$, and $72^{\circ} \mathrm{C}$ for $30 \mathrm{~s}$, and one cycle at $72^{\circ} \mathrm{C}$ for $7 \mathrm{~min}$. The $18 \mathrm{~S}$ ribosomal RNA was amplified for 18 cycles under the same conditions. PCR products were separated on $2 \%$ agarose gels (Duchefa, The Netherlands), detected by the gel documentation system (Kodak, USA), and semi-quantified (KODAK). Sequences of the primers used for PCR are shown in Supplementary Table S1. qPCR reactions were performed in $25 \mu \mathrm{l}$ volumes containing $1 \mathrm{X} \mathrm{SYBR}^{\circledR}$ Green PCR master mix (Roche, Germany), $0.2 \mu \mathrm{M}$ of each forward and reverse primer (Macrogen), and $1.0 \mu \mathrm{l}$ of cDNA. PCR was performed with a Lightcycler $^{\circledR} 480$ Sequence Detection System (Roche) under the following conditions: denaturation at $95^{\circ} \mathrm{C}$ for $5 \mathrm{~min}$, then 45 cycles at $95^{\circ} \mathrm{C}$ for $15 \mathrm{~s}, 60^{\circ} \mathrm{C}$ for $15 \mathrm{~s}$, and $72^{\circ} \mathrm{C}$ for $15 \mathrm{~s}$. The comparative $\mathrm{C}_{\mathrm{T}}$ method $\left(\Delta \Delta \mathrm{C}_{\mathrm{T}}\right)$ was used for quantification: $\Delta \mathrm{C}_{\mathrm{T}}=\mathrm{C}_{\mathrm{T}}$ (target gene) - $\mathrm{C}_{\mathrm{T}}$ (reference gene), and $\Delta \Delta \mathrm{CT}=\Delta \mathrm{C}_{\mathrm{T}}$ (sample) $\Delta \mathrm{C}_{\mathrm{T}}$ (control). Relative quantification was derived by $2^{-\Delta \Delta \mathrm{CT}}$. Primers are shown in Supplementary Table S2.

\section{Protein stability assay}

The protein stability assay was performed as described previously (Yoo et al., 2014). In brief, cells were transfected with $1.0 \mu \mathrm{g}$ of plasmids or $50 \mathrm{nM}$ of siRNA for $48 \mathrm{~h}$, after which 100 $\mu \mathrm{g} / \mathrm{ml}$ of cycloheximide (Sigma, USA) was added to block protein synthesis. Cells were harvested at each time point indicated in the figures, and cell lysates were analyzed by immuneblotting.

\section{Immunofluorescence staining}

Immunofluorescence assay was performed as described previously (Yoo et al., 2009; 2014). In brief, HeLa cells were grown on glass coverslips coated in poly-D-lysine $(0.1 \mathrm{mg} / \mathrm{ml}$, Sigma) and extracted in Triton X-100 buffer $(0.5 \%$ Triton X-100, $20 \mathrm{mM}$ HEPES-KOH pH 7.4, $50 \mathrm{mM} \mathrm{NaCl}, 3 \mathrm{mM} \mathrm{MgCl} 2$ and $300 \mathrm{mM}$ sucrose). Fixation was then carried out with $4 \%$ paraformaldehyde $/ 2 \%$ sucrose in PBS for 30 min, after which the cells were permeabilized with Triton X-100 buffer for 20 min at RT. After blocking with $5 \%$ BSA in PBS for $1 \mathrm{~h}$, cells were incubated with anti-PinX1 (1:100, Abnova), anti-HA-probe (1:200, Santa Cruz) or anti-Fibrillarin $\left(1: 400\right.$, Abcam) at $4^{\circ} \mathrm{C}$ overnight. Cells were then washed with cold PBS and incubated with Alexa Fluor ${ }^{\circledR}$ anti-mouse or rabbit lgG-488-green (1:500, Invitrogen), Alexa Fluor $^{\circledR}$ anti-rabbit IgG-633-red (1:500, Invitrogen) for $1 \mathrm{~h}$ at RT 


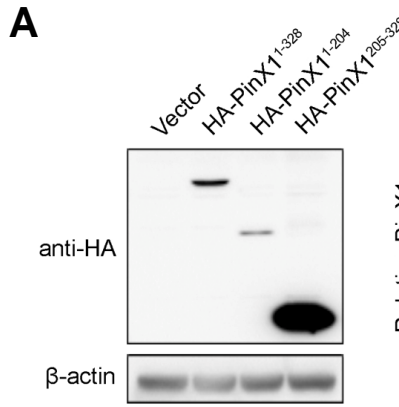

\section{B}

C

D

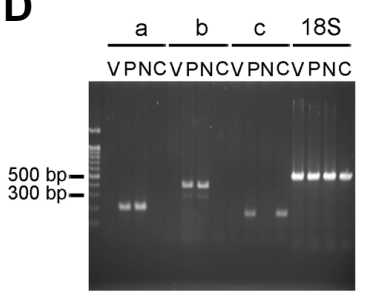

$\mathrm{V}=$ Vector

$\mathrm{P}=\mathrm{HA}-\mathrm{Pin} X 1^{1-328}$

$\mathrm{N}=\mathrm{HA}-\mathrm{Pin} X 1^{1-204}$

$\mathrm{C}=\mathrm{HA}-\mathrm{Pin} X 1^{205-328}$
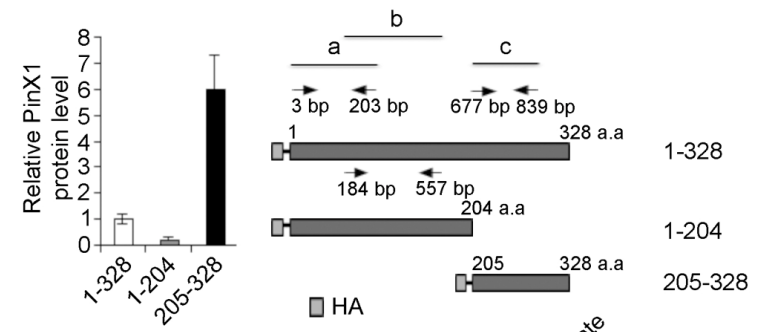

\section{$E$}

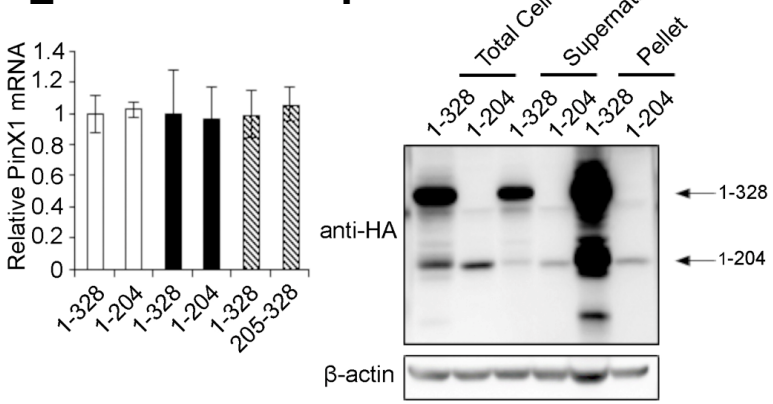

Fig. 1. Expression of $H A$-tagged $P i n X 1$ truncations in HeLa cells. (A) Expression of HA-tagged PinX1 derivatives. HeLa cells transfected with PinX1 truncation mutants for $48 \mathrm{~h}$ were subjected to immunoblotting. $\beta$-actin was used as a loading control. (B) Quantification of PinX1 protein represented in A. PinX1 level normalized to $\beta$-actin was quantified as the ratio relative to $\mathrm{HA}-\mathrm{PinX} 1^{1-328}$. Error bars were derived from three independent experiments. (C) Location of $\mathrm{PCR}$ primers in PinX1. Three pairs of PCR primers were indicated as $a, b$, and C. (D) RT-PCR showing levels of the HAPinX1 derivatives. Total RNA was isolated from HeLa cells transfected with the indicated plasmids. RT-PCR was performed for PinX1 using the primers shown in $\mathrm{C}$, indicated as $\mathrm{a}, \mathrm{b}$, and $\mathrm{c}$. PinX1 and 18S rRNA were amplified for 20 and 18 cycles, respectively, and stained with ethidium bromide. (E) Quantification of relative PinX1 mRNA levels represented in D. PinX1 normalized to 18S rRNA was quantified as the ratio relative to HA-PinX1 $1^{1-328}$. Error bars were

derived from two independent experiments. $(F)$ Fractionation of cell lysates. Cells collected at 2 days post-transfection were lysed by the freeze-thaw method, and fractions of supernatant and pellet were obtained after centrifugation of total cell lysates. A whole pellet resuspended in $10 \mu \mathrm{L}$ of loading buffer and $40 \mu \mathrm{g}$ of each of the total cell lysates and supernatants were loaded, followed by immunoblotting.

(keep in dark) before incubating with $1.0 \mu \mathrm{g} / \mathrm{ml}$ of DAPI $(1.0$ $\mathrm{mg} / \mathrm{ml}$ ) (Sigma) for DNA staining. Coverslips were mounted with ProLong ${ }^{\circledR}$ Gold anti-fade reagent (Invitrogen) and sealed with nail polish. Images were acquired by confocal microscopy (Leica, Germany) using the operating software with the Leica Application Suite AF Lite system (Leica).

\section{RESULTS}

Expression of HA-tagged PinX1 derivatives in HeLa cells In the course of experimentation, we noticed that PinX1 truncation mutants were detected at different levels upon transfection. HA-tagged PinX1 ${ }^{205-328}$, the C-terminal of PinX1, was relatively abundant compared to the N-terminal of PinX1, HA-PinX $1^{1-204}$ The level of HA-PinX $1^{1-204}$ was as low as $5 \%$ that of HA-PinX $1^{1-}$ ${ }^{328}$, whereas HA-PinX1 $1^{205-328}$ exhibited nearly six-fold higher level than HA-PinX1 $1^{1-328}$ (Figs. $1 \mathrm{~A}$ and $1 \mathrm{~B}$ ). To test whether the differences in the levels of protein were derived by the efficiency of transcription, the levels of mRNA of the PinX1 truncations were determined by RT-PCR with three pairs of primers (Fig. 1C). PCR was performed with a condition that endogenous PinX1 remained undetected by using low number of cycles. Note that there is no PinX1 band in vector samples which exhibit $18 \mathrm{~S}$ rRNA similar levels to other samples (Fig. 1D). The results showed no significant differences in the mRNA levels between HA-PinX $1^{1-328}$ and HA-PinX $1^{1-204}$, or between HAPinX $1^{1-328}$ and HA-PinX $1^{205-328}$, indicating that the efficiency of transcription was unlikely to contribute to the levels of the proteins (Figs. 1D and 1E). It was also possible that HA-PinX1 ${ }^{1-204}$ was aggregated in the pellet fraction during analysis, with only a small portion of the protein remaining in the supernatant frac- tions. To test this possibility, HA-PinX $1^{1-328}$ and HA-PinX $1^{1-204}$ were examined in total cell lysates as well as in both fractions of pellet and supernatant. The results showed low levels of HA$\mathrm{PinX} 1^{1-204}$ in the total cell lysates, while insignificant amounts of the protein were present in the pellet fraction. Note that the whole fraction was loaded for the pellet while only a portion was loaded for the supernatants (Fig. 1F). Taken together, this indicated that the PinX1 truncations were accumulated at different levels, and particularly, that the low levels of the N-terminal of PinX1 were not to be due to weak transcriptional activity or aggregation of the protein in the pellet fraction.

The C-terminal of PinX1 is more stable than the $\mathrm{N}$-terminal To address the possibility that PinX1 truncation mutants have different levels of protein stability, stability assay was performed as follows: HeLa cells were transfected with HA-PinX $1^{1-328}$, HA$\mathrm{PinX} 1^{1-204}$, or HA-PinX $1^{205-328}$, and then treated with cycloheximide $(\mathrm{CHX})$ after $48 \mathrm{~h}$ for the indicated times to block protein biosynthesis. The level of HA-tagged PinX1 protein was monitored by immunoblot (Figs. $2 \mathrm{~A}$ and $2 \mathrm{~B}$ ). HA-PinX1 ${ }^{205-328}$ remained abundant upon increased exposure time to $\mathrm{CHX}$, whereas HA-PinX $1^{1-204}$ was rapidly degraded. The assay performed with a shorter time of exposure to $\mathrm{CHX}$ confirmed different levels of stability according to the truncated form of PinX1 (Figs. $2 \mathrm{C}$ and $2 \mathrm{D}$ ). HA-PinX $1^{1-328}$ was degraded relatively faster than HA-PinX $1^{205-328}$, but slower than HA-PinX11-204 (Fig. 2). These results led us to speculate that the $\mathrm{N}$-terminal region of $\mathrm{PinX} 1$ may negatively affect the stability of the protein. To test this possibility, GFP-fused or myc-tagged PinX $1^{1-328}$ was subjected to stability assays (Supplementary Fig. S1). Unlike HA- PinX1, both GFP-PinX1 and myc-PinX1 showed almost equal 


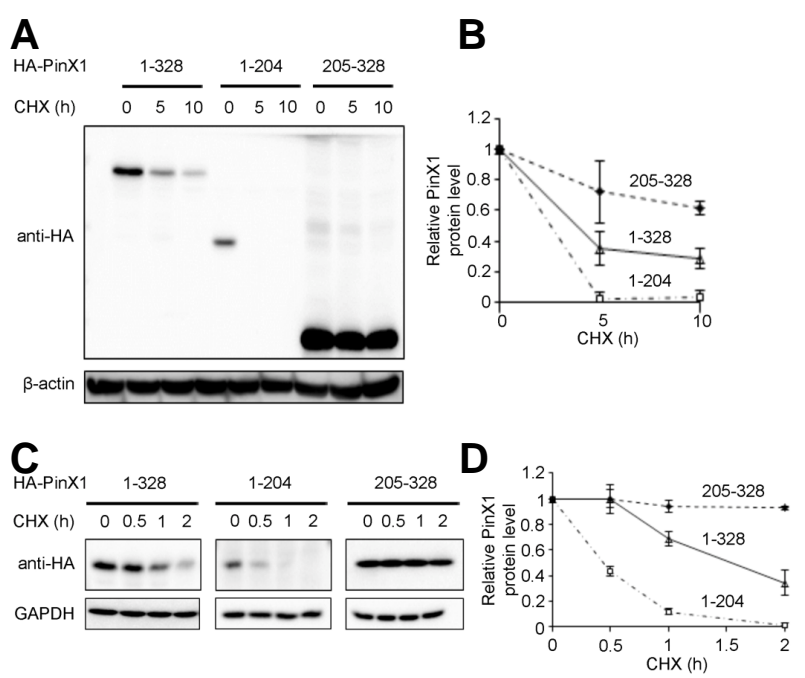

Fig. 2. Protein stability of $\mathrm{HA}$-tagged PinX1 derivatives in HeLa cells. (A) Protein stability of PinX1 truncations. HeLa cells transfected with PinX1 truncations for $48 \mathrm{~h}$ were treated with cycloheximide for the indicated times, followed by immunoblot. (B) Quantification of PinX1 protein represented in $\mathrm{A}$. PinX1 level normalized to $\beta$-actin level was quantified as the ratio relative to the level at the $0 \mathrm{~h}$ time point, and the error bars were derived from three independent experiments. (C) Protein stability of PinX1 truncations with a shorter exposure time to $\mathrm{CHX}$. Cells were prepared as described in $\mathrm{A}$ and treated with cycloheximide for the indicated times, followed by immunoblot. GAPDH was used as a loading control. (D). Quantification of PinX1 protein represented in C. PinX1 level normalized to GAPDH level was quantified as described in B. Error bars were derived from two independent experiments.

stability to the C-terminal of PinX1, suggesting that the HA-tag rather than the $\mathrm{N}$-terminal of PinX1 exerted a negative effect on the stability of full-length PinX1. We do not fully understand how the HA tag could reduce the stability of the full length of PinX1. Nevertheless, consistent with the findings of HA-tagged PinX1 truncations, myc-PinX $1^{205-328}$ was more stable than myc-PinX $1^{1-204}$ (Supplementary Fig. S1).

It was reported that residues 290 to 328 of PinX1 are responsible for its nucleolar localization (Chen et al., 2010). Therefore, we examined the localization of PinX1 truncation mutants via immunostaining, which indeed showed that HA$\mathrm{Pin} X 1^{1-328}$ and HA-PinX $1^{205-328}$ were localized in the nucleoli, while HA-PinX $1^{1-204}$ was found in the nucleoplasm (Supplementary Fig. S2), confirming that the nucleolar forms of PinX1 are more stable than the nuclear form of PinX1.

It was previously reported that a fraction of TERT is found in the nucleolus (Tomlinson et al., 2006). Since both TERT and PinX1 are localized in the nucleolus, we wondered whether the localization of PinX1 to the nucleolus is affected by TERT. To address this possibility, HeLa cells were transfected with siTERT or TERT-myc for $48 \mathrm{~h}$, followed by immunostaining with anti-PinX1 antibody. The results showed no apparent changes in the nucleolar localization of PinX1 upon depletion or overexpression of TERT (Supplementary Fig. S3). TERT status in the cells was verified by quantitative RT-PCR (qRT-PCR), which was prepared in parallel (Supplementary Fig. S3). These results indicate that TERT does not control PinX1 localization to the nucleolus.
TERT stabilizes nucleolar forms of PinX1

In a previous study, we found GFP-PinX1 to be less abundant in TERT-depleted cells, which were generated by treatment with siRNA targeting TERT, named siTERT (Yoo et al., 2014). To explore the functional connection between TERT and PinX1, endogenous PinX1 protein was measured in siTERT-treated HeLa cells (Fig. 3A). Cells transfected with siTERT for $48 \mathrm{~h}$, which showed no noticeable changes on cell growth, were subjected to immunoblotting and qRT-PCR. Immunoblotting revealed that the level of PinX1 protein was slightly decreased in siTERT-treated cells compared to the control cells although the effect was mild $(0.87 \pm 0.143, n=9, p=0.027)$ (Fig. $3 A)$. PinX1 mRNA was also measured by qRT-PCR to ensure that there was no off-target effect of siTERT (Fig. 3B), and TERT status was verified by qRT-PCR (Fig. 3B). Next, the level of PinX1 protein was measured in cells transfected with TERTmyc. Expression of TERT-myc was verified by immunoblotting (Fig. 3C) and/or qRT-PCR $\left(1 \times 10^{3}-1 \times 10^{4}\right.$ of TERT mRNA in TERT-myc-transfected cells versus 1.0 in the vector cells, data not shown). Immunoblotting showed that the level of PinX1 rather varied among the assays (Fig. $3 \mathrm{C}$ ). We further examined the level of PinX1 protein in the ALT cell line GM847 and in stable TERT-expressing GM847 cells (Jung et al., 2013). Interestingly, PinX1 protein was more abundant in the TERT-expressing GM847 cells $(1.5 \pm 0.07)$ than in the TERT-negative GM847 cells (Fig. 3D). The increase in PinX1 accumulation in response to excess TERT presented in Fig. $3 \mathrm{D}$ are more convincing probably because the amplitude of the variations in TERT levels are larger. Based on these results, it was tempting to speculate that there might be a role of TERT on PinX1 accumulation. To address this possibility, we investigated whether the stability of PinX1 protein is affected by TERT. A PinX1 stability assay was performed in TERTdepleted and -overexpressing cells. The assays showed that PinX1 was degraded more rapidly in the siTERT-treated cells compared to the siControl-treated cells upon treatment with CHX (Figs. 4A and 4B). Depletion of TERT in the samples was verified by qRT-PCR (Fig. 4C). In contrast, PinX1 was more stably maintained in the TERT-myc-expressing cells compared to vector-transfected cells (Figs. 4D and 4E). Again, amplification of TERT in the samples was verified by immunoblotting (Fig. 4D) and/or qRT-PCR (data not shown). Our findings reveal that the stability of PinX1 is maintained in the presence of TERT.

Next, it was examined whether the TERT-mediated increase in PinX1 stability varies according to the PinX1 truncations by measuring the stability of the PinX1 truncation mutants in TERT-depleted and -overexpressing cells (Fig. 5). HeLa cells were co-transfected with the PinX1 truncations along with siTERT or TERT-myc, and then treated with $\mathrm{CHX}$ for the indicated times. Like endogenous PinX1, HA-PinX $1^{1-328}$ and HA$\mathrm{PinX} 1^{205-328}$ were degraded more rapidly in the TERT-depleted cells (Figs. 5A and $5 B$ ) and were more stable in the TERT-mycexpressing cells (Figs. $5 \mathrm{D}$ and $5 \mathrm{E}$ ) compared to each of the control cells. However, HA-PinX $1^{1-204}$ was degraded in both the TERT-depleted and -overexpressing cells, with no difference to the control cells (Fig. 5). TERT status in the samples was verified by either qRT-PCR (Fig. 5C) or immunoblot (Fig. 5D), and expression of TERT-myc in the reaction of PinX ${ }^{205-328}$ (Fig. 5D) was also verified by qRT-PCR (data not shown). Collectively, our findings indicate that TERT stabilizes the nucleolar form of PinX1, not the nuclear form. 
A
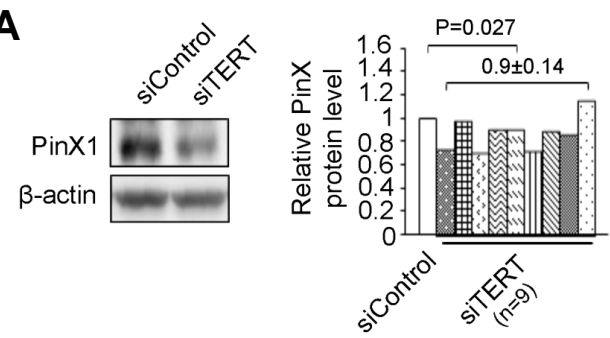

C
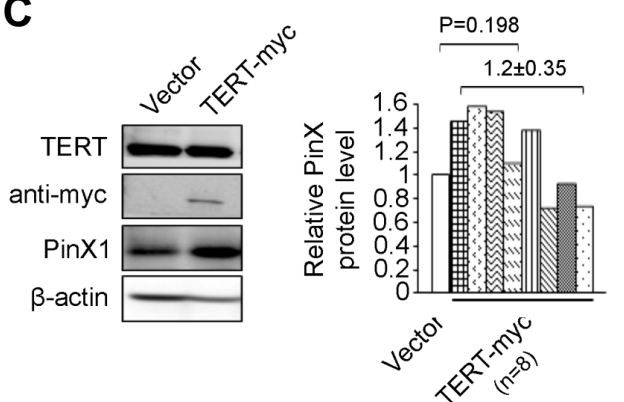

B

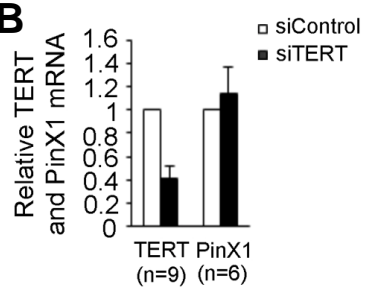

D

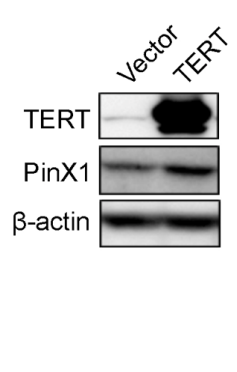

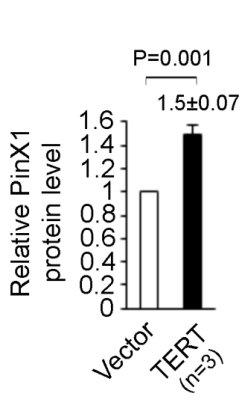

Fig. 3. Effect of TERT on the accumulation of PinX1. (A) PinX1 level in TERTdepleted cells. Cell lysates prepared from HeLa cells transfected with $50 \mathrm{nM}$ of siTERT or siControl for $48 \mathrm{~h}$ were subjected to immunoblotting. PinX1 normalized to $\beta$-actin was quantified as the ratio relative to siControl-treated cells, shown in the graph on the right. (B) qRT-PCR for TERT and PinX1 in the samples shown in A. Total RNA isolated from a portion of the cells tested in A was subjected to qRT-PCR. mRNA levels were quantified using the $2^{-\Delta \Lambda C T}$ method, for which $\beta$-actin was determined as an internal control. TERT and PinX1 were detected from nine and six assays shown in A, respectively. (C) PinX1 level in TERT-myc expressing cells. Cell lysates prepared from HeLa cells transfected with TERT-myc or vector for $48 \mathrm{~h}$ were subjected to immunoblo- tting. PinX1 protein was quantified as described in

A. (D) Abundance of PinX1 in TERT-expressing ALT cells. PinX1 was detected in GM847/TERT and GM847/vector, stable cell lines by immunoblot. PinX1 protein was quantified as described previously from three independent experiments. The Student's t-test was used for statistical analysis. $P$-values at 0.05 or smaller were deemed statistically significant.

$\boldsymbol{A}$

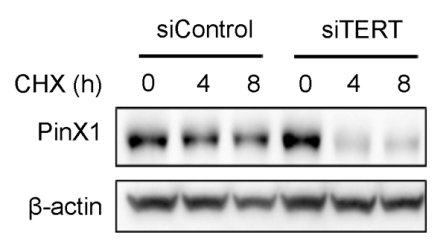

D

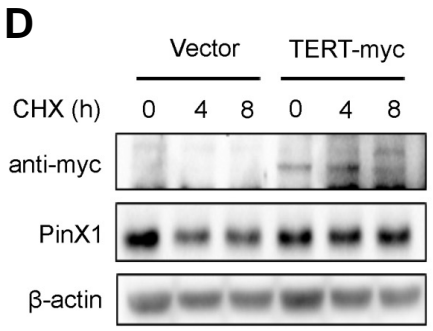

B

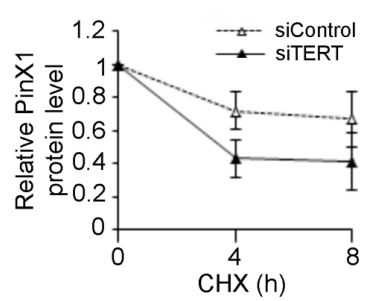

$E$

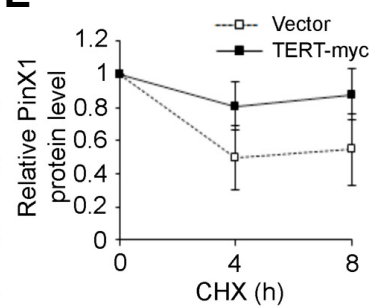

C

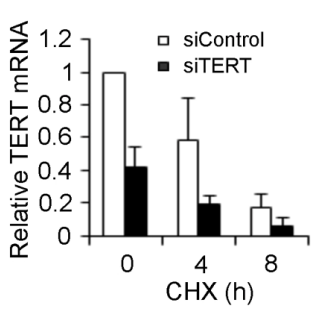

$\mathrm{CHX}(\mathrm{h})$

Fig. 4. TERT positively regulates the stability of PinX1. (A) PinX1 protein is less stable in TERT-depleted cells. HeLa cells transfected with siTERT for $48 \mathrm{~h}$ were treated with cycloheximide (CHX) for the indicated times, followed by immunoblot. (B) Quantification of PinX1 represented in $A$. PinX1 level normalized to $\beta$-actin was quantified relative to the level at $0 \mathrm{~h}$. (C) qRT-PCR for TERT in the samples shown in A. Total RNA isolated from a portion of the cells tested in A was subjected to qRTPCR. TERT mRNA was quantified using the $2^{-\triangle \Delta C T}$ method, for which $\beta$ actin was determined as an internal control. TERT mRNA detected in siControl-treated cells at $0 \mathrm{~h}$ was defined as 1.0. (D) PinX1 protein is more stable in TERT-overexpressing cells.

HeLa cells transfected with TERT-myc or vector for $48 \mathrm{~h}$ were treated with cycloheximide for the indicated times, and lysates were prepared for immunoblot. PinX1, TERT-myc, and $\beta$-actin were detected. (E) Quantification of PinX1 represented in D. PinX1 level was quantified as described in $B$. Error bars shown in graphs $B$ and $C$ represent the S.D. of the mean from three independent experiments and those in $E$ from five independent assays.

\section{DISCUSSION}

In this study, we found that PinX1 and TERT are functionally connected regarding the stability of PinX1, and suggest for the first time a role of TERT in the maintenance of PinX1 homeostasis. The C-terminal of PinX1, a nucleolar fragment, is more stable than the $\mathrm{N}$-terminal of PinX1, a nuclear fragment, suggesting that PinX1 retains stability in nucleolus. It is tempting to speculate that post-translational modification may be involved in the maintenance of PinX1 homeostasis. For instance, Pololike kinase 1, Plk1, is known to phosphorylate PinX1 in vivo and in vitro, and promotes protein turnover of PinX1 via ubiquitinmediated proteolysis (Wang et al., 2010). It would be interesting to know where the Plk1-mediated phosphorylation of PinX1 occurs; suppression in the nucleolus or activation in the nucleoplasm. Nonetheless, further studies are needed to elucidate the molecular mechanism underlying the regulation of PinX1 levels through modulating subcellular translocation. 

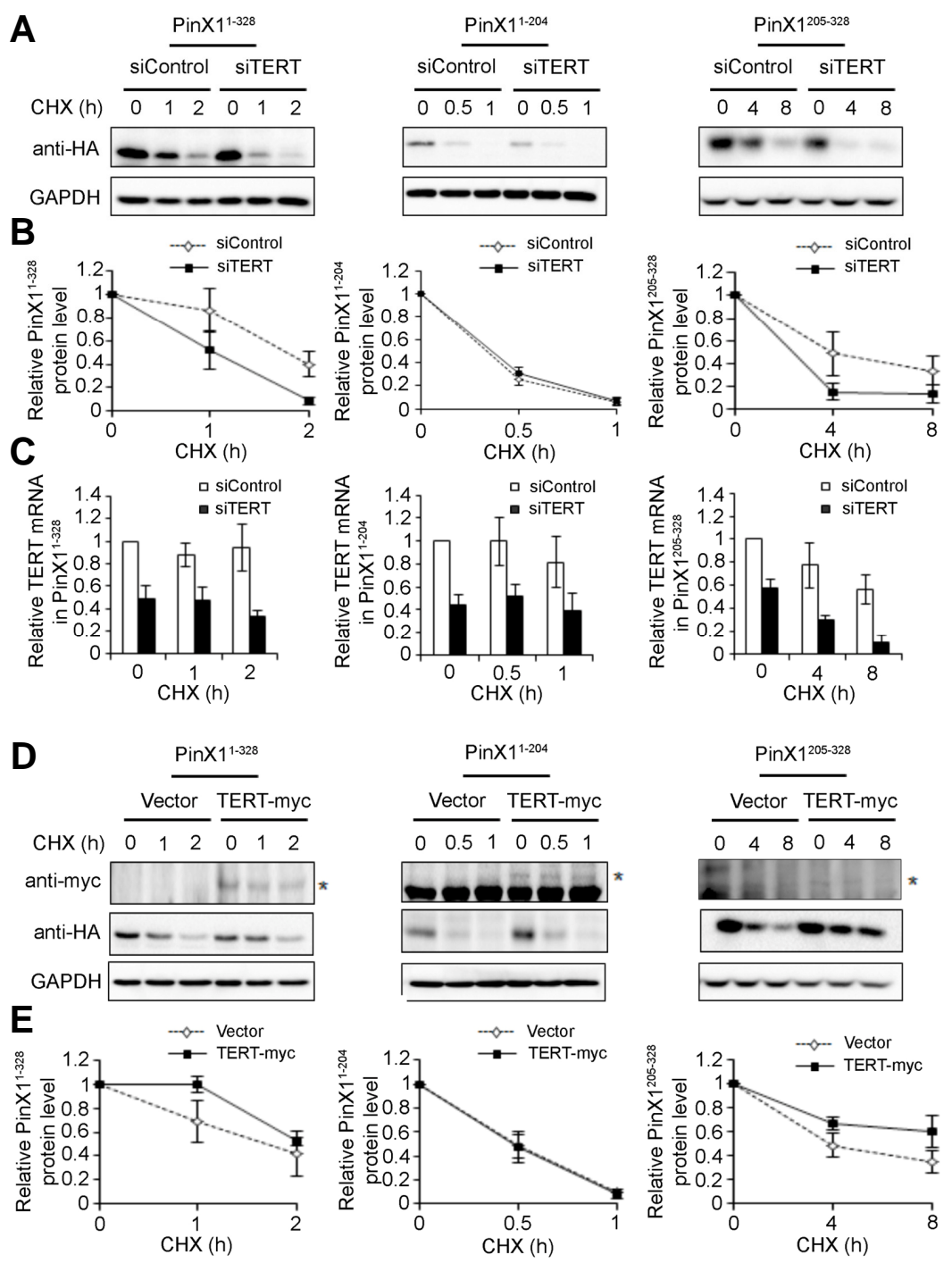

Fig. 5. TERT stabilizes the nucleolar form of PinX1. (A) Depletion of TERT reduces the stability of nucleolar forms of PinX1. HeLa cells were transfected with siTERT, and $24 \mathrm{~h}$ later, cells were transfected with HA-tagged PinX1 truncations for another $24 \mathrm{~h}$, and then treated with cycloheximide ( $\mathrm{CHX}$ ) for the indicated times. PinX1 truncations were detected with anti-HA antibody, and GAPDH was used as an internal control. (B) Quantification of PinX1 represented in A. PinX1 level normalized to GAPDH was quantified relative to the level at $0 \mathrm{~h}$. (C) qRT-PCR confirming TERT status in the samples used in A. qRT-PCR was performed with SyBR Green reagents, and $\beta$-actin was used as a control. (D) Excess TERT stabilizes nucleolar forms of PinX1. HeLa cells transfected with TERTmyc for $24 \mathrm{~h}$ were transfected with HAtagged PinX1 truncations for another $24 \mathrm{~h}$, and then treated with $\mathrm{CHX}$ for the indicated times, and lysates were prepared for immnoblot. TERT-myc was indicated by asterisks. (E) Quantification of PinX1 protein represented in D. PinX1 level normalized to GAPDH was quantified relative to the level at $0 \mathrm{~h}$. Error bars shown in graphs $\mathrm{B}, \mathrm{C}$, and $\mathrm{E}$ represent the S.D. of the mean from three independent experiments.

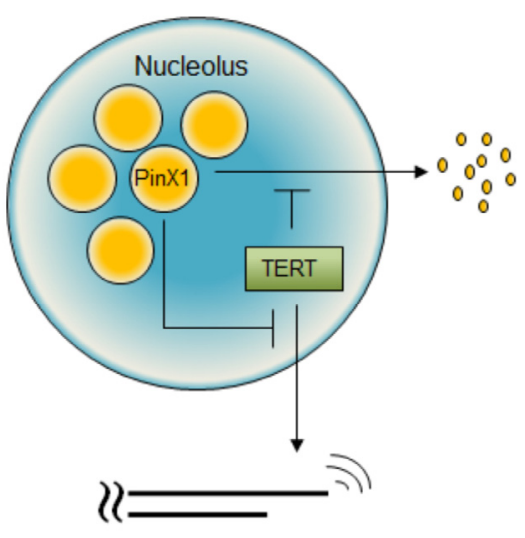

Telomere Elongation

Fig. 6. A proposed model of the accumulation of PinX1 in the nucleolus. TERT increases the stability of PinX1, which results in the accumulation of PinX1 in the nucleolus. Accumulated PinX1 sequesters TERT in the nucleolus, which may impair telomere elongation.
PinX1 was rapidly degraded in TERT-depleted cells, and stably maintained under conditions of excess TERT. This effect, however, was not evident in a nuclear form of PinX1. We found that the subcellular localization of PinX1 was not altered by TERT, which indicates that the nucleolar localization of PinX1 is independent of TERT. Our findings reveal that TERT does not control PinX1 localization to nucleolus but has an effect on the stability of nucleolar PinX1. These led us to speculate that functional interaction between PinX1 and TERT takes place in the nucleolus. Given that the C-terminal of PinX1 is responsible for TERT binding and nucleolar localization (Chen et al., 2010), PinX1 may gain stability in the nucleolus through interaction of the C-terminal region with TERT (Fig. 6). However, it is not clear yet whether the observed effects could result from a direct stabilization of PinX1 by TERT, or alternatively indirect mechanisms. To provide more convincing evidence that TERT directly promotes PinX1 stabilization, the physical association between TERT and PinX1 needs to be examined using co-immunoprecipitation whether it increases upon TERT overexpression.

Truncated PinX1 showed different localization, either in the nucleolus or nucleoplasm. Unlike our previous report that HA- 
PinX $1^{205-328}$ was located in the nucleoplasm (Yoo et al., 2009), this truncated form of PinX1 was found in the nucleolus in the present study. The previous finding was presumably caused by inadequate permeabilization (Yoo et al., 2009). It was now confirmed that the C-terminal region of PinX1 is necessary and sufficient for its localization in the nucleolus, and further, its stability. Lin et al. (2007) showed that ectopic overexpression of PinX1 resulted in nucleolar accumulation of TERT in human cancer cells. As proposed in a previous report (Lin and Blackburn, 2004), TERT is sequestered in the nucleolus by the accumulated PinX1, which in turn impairs the action of TERT on telomeres (Fig. 6). Although highly speculative, it is possible that TERT controls telomere length in two stages: first, TERT elongates telomeres as a positive regulator of telomere length; second, when the telomere becomes too long, TERT isolates itself in the nucleolus by accumulating PinX1 (Fig. 6). Further studies are needed to reveal the precise mechanism of TERTmediated PinX1 turnover, which will provide insight into the mechanism of telomere regulation mediated by telomerase.

Note: Supplementary information is available on the Molecules and Cells website (www.molcells.org).

\section{ACKNOWLEDGMENTS}

This work was supported by Basic Science Research Program through the National Research Foundation of Korea (NRF) funded by the Ministry of Education (2010-0008254, 2014R 1A1A2054542 to BKO, 2013R1A1A2009090 to YHS), by the Ministry of Science, ICT \& Future Planning (2011-0015638 to BKO), by Hanyang University (201200000002989 to JSC), and partly by Konkuk University's research support program for its faculty on sabbatical leave in 2013 to YHS.

\section{REFERENCES}

Autexier, C., and Lue, N.F. (1998). The structure and function of telomerase reverse transcriptase. Annu. Rev. Biochem. 75, 493517

Avilion, A.A., Piatyszek, M.A., Gupta, J., Shay, J.W., Bacchetti, S., and Greider, C.W. (1996). Human telomerase RNA and telomerase activity in immortal cell lines and tumor tissues. Cancer Res. $56,645-650$

Banik, S.S., and Counter, C.M. (2004). Characterization of interactions between PinX1 and human telomerase subunits hTERT and hTR. J. Biol. Chem. 279, 51745-51748.

Beattie, T.L., Zhou, W., Robinson, M.O., and Harrington, L. (1998). Reconstitution of human telomerase activity in vitro. Curr. Biol. 8 , 177-180.

Bryan, T.M., and Reddel, R.R. (1997). Telomere dynamics and telomerase activity in in vitro immortalised human cells. Eur. J. Cancer. 33, 767-773.

Chen, G., Da, L., Xu, Y., Xu, M., Song, L., Li, T., and Zhao, M. (2010). C-terminal amino acids 290-328 of LPTS/PinX1 confer telomerase inhibition. Biochem. Biophys. Res. Commun. 398, 683-689.

Cheung, D.H., Kung, H.F., Huang, J.J., and Shaw, P.C. (2012). PinX1 is involved in telomerase recruitment and regulates telomerase function by mediating its localization. FEBS Lett. 586, 3166-3171.

Counter, C.M., Meyerson, M., Eaton, E.N., Ellisen, L.W., Caddle, S.D., Haber, D.A., and Weinberg, R.A. (1998). Telomerase activity is restored in human cells by ectopic expression of hTERT (hEST2), the catalytic subunit of telomerase. Oncogene 16, 1217-1222.

Djojosubroto, M.W., Yoon, S.C., Lee, H.W., and Rudolph, K.L. (2003). Telomeres and telomerase in aging, regeneration and cancer. Mol. Cells 15,164-175.

Etheridge, K.T., Banik, S.S., Armbruster, B.N., Zhu, Y., Terns, R.M., Terns, M.P., and Counter, C.M. (2002). The nucleolar localization domain of the catalytic subunit of human telomerase. J. Biol. Chem. 277, 24764-24770.
Hahn, W.C., Stewart, S.A., Brooks, M.W., York, S.G., Eaton, E., Kurachi, A., Beijersbergen, R.L, Knoll, J.H.M, Meyerson, M., and Weinberg, R.A. (1999). Inhibition of telomerase limits the growth of human cancer cells. Nat. Med. 5, 1164-1170.

Herbert, B.S., Pitts, A.E., Baker, S.I., Hamilton, S.E., Wright, W.E., and Shay, J.W., Corey, D.R. (1999). Inhibition of human telomerase in immortal human cells leads to progressive telomere shortening and cell death. Proc. Natl. Acad. Sci. USA. 96, 14276-14281.

Jung, A.R., Yoo, J.E., Shim, Y.H., Choi, Y.N., Jeung, H.C., Chung, H.C., Rha, R.Y, and Oh, B.K. (2013). Increased alternative lengthening of telomere phenotypes of telomerase-negative immortal cells upon trichostatin-a treatment. Anticancer Res. 33, 821829.

Lin, J., and Blackburn, E.H. (2004). Nucleolar protein PinX1p regulates telomerase by sequestering its protein catalytic subunit in an inactive complex lacking telomerase RNA. Genes Dev. 18, 387-396.

Lin, J., Jin, R., Zhang, B., Yang, P.X., Chen, H., Bai, Y.X., Xie, Y., Huang, C., and Huang, J. (2007). Characterization of a novel effect of hPinX1 on hTERT nucleolar localization. Biochem. Biophys. Res. Commun. 353, 946-952.

Lingner, J., Hughes, T.R., Shevchenko, A., Mann, M., Lundblad, V., and Cech, T.R. (1997). Reverse transcriptase motifs in the cataIytic subunit of telomerase. Science 276, 561-567.

McEachern, M.J., Krauskopf, A., and Blackburn, E.H. (2000). Telomere and their control. Annu. Rev Genet 34, 331-358.

Meyerson, M., Counter, C.M., Eaton, E.N., Ellisen, L.W., Steiner, P., Caddle, S.D., Ziaugra, L., Beijersbergen, R.L, Davidoff, M.J., Liu, Q., et al. (1997). hEST2, the putative human telomerase catalytic subunit gene, is up-regulated in tumor cells and during immortalization. Cell 90, 785-795.

Nakamura, T.M., Morin, G.B., Chapman, K.B., Weinrich, S.L., Andrews, W.H., Lingner, J., Harley, C.B, and Cech, T.R. (1997) Telomerase catalytic subunit homologs from fission yeast and human. Science 277, 955-959.

Nakayama, J., Tahara, H., Tahara, E., Saito, M., Ito, K., Nakamura, H., Nakanishi, T., Tahara, E., Ide, T., and Ishikawa, F. (1998). Telomerase activation by hTRT in human normal fibroblasts and hepatocellular carcinomas. Nat. Genet. 18, 65-68.

Palm, W., and de Lange, T. (2008). How shelterin protects mammalian telomeres. Annu. Rev. Genet. 42, 301-334.

Tomlinson, R.L., Ziegler, T.D., Supakorndej, T., Terns, R.M., and Terns, M.P. (2006). Cell cycle-regulated trafficking of human telomerase to telomeres. Mol. Biol. Cell 17, 955-965.

Wang, C., Yu, J., Yuan, K., Lan, J., Jin, C., and Huang, H. (2010). Plk1-mediated mitotic phosphorylation of PinX1 regulates its stability. Eur. J. Cell Biol. 89, 748-756.

Wong, J.M., Kusdra, L., and Collins, K. (2002). Subnuclear shuttling of human telomerase induced by transformation and DNA damage. Nat. Cell Bio. 4, 731-736.

Yang, Y., Chen, Y., Zhang, C., Huang, H., and Weissman, S.M. (2002). Nucleolar localization of hTERT protein is associated with telomerase function. Exp. Cell Res. 277, 201-209.

Yoo, J.E., Oh, B.K., and Park, Y.N. (2009). Human PinX1 mediates TRF1 accumulation in nucleolus and enhances TRF1 binding to telomeres. J. Mol. Biol. 388, 928-940.

Yoo, J.E., Park, Y.N., and Oh, B.K. (2014). PinX1, a telomere repeat-binding factor 1 (TRF1)-interacting protein, maintains telomere integrity by modulating TRF1 homeostasis, the process in which human telomerase reverse Transcriptase (hTERT) plays dual roles. J. Biol. Chem. 289, 6886-6898.

Zhang, X., Mar, V., Zhou, W., Harrington, L., and Robinson, M.O. (1999). Telomere shortening and apoptosis in telomeraseinhibited human tumor cells. Genes Dev. 13, 2388-2399.

Zhang, B., Bai, Y.X., Ma, H.H., Feng, F., Jin, R., Wang, Z.L., Lin, J., Sun, S.P., Yang, P., Wang, X.X., et al. (2009). Silencing PinX1 compromises telomere length maintenance as well as tumorigenicity in telomerase-positive human cancer cells. Cancer Res. 69, 75-83.

Zhou, X.Z., and Lu, K.P. (2001). The Pin2/TRF1-interacting protein PinX1 is a potent telomerase inhibitor. Cell 107, 347-359.

Zhou, X.Z., Huang, P., Shi, R., Lee, T.H., Lu, G., Zhang, Z., Bronson, R., and Lu, K.P. (2011). The telomerase inhibitor PinX1 is a major haploinsufficient tumor suppressor essential for chromosome stability in mice. J. Clin. Invest. 121, 1266-1282. 